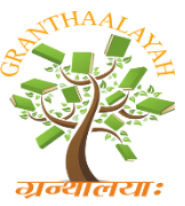

INTERNATIONAL JOURNAL OF RESEARCH GRANTHAALAYAH A knowledge Repository

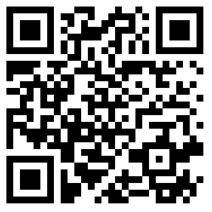

Arts

\title{
MASK: A CREATIVE REPRESENTATION OF FUNCTIONAL ART
}

\author{
Dr. Anjali Pandey *1 \\ ${ }^{* 1}$ Associate Prof \& H.O.D., Department Drawing \&Painting, Govt. M.L.B. Girls P. G. \\ Autonomous College Bhopal, India
}

\begin{abstract}
Masks are used all over the world for their expressive power. It is an important part of theatre and rituals. It is generally used to conceal the identity or to transform the character. In India the festival mask are used to represent the deities and mythological character in dance and drama performance as well as in many ceremonial functions, religious and social rituals and in entertainment since ancient time. The evidences of mask could also be seen since prehistoric age. Many tribes of India mask are used in rituals and performances. The masks of different region are distinct and peculiar in size, shape, form, design and material used. In early era the masks were made in simplified form, now some innovative decorations have changed their aesthetic value.
\end{abstract}

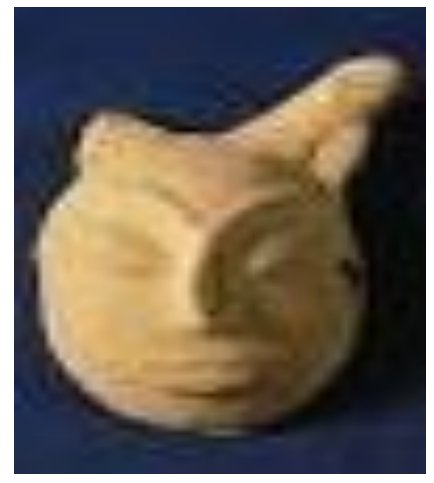

Keywords: Living Culture; Prehistoric Era; Ceremonial Functions; Costumes; Entertainment; Transform; Regional; Paper Machie; Wood; Zari Painting; Designs.

Cite This Article: Dr. Anjali Pandey (2019). "MASK: A CREATIVE REPRESENTATION OF FUNCTIONAL ART." International Journal of Research - Granthaalayah, 7(4), 90-96. https://doi.org/10.29121/granthaalayah.v7.i4.2019.878.

\section{Introduction}
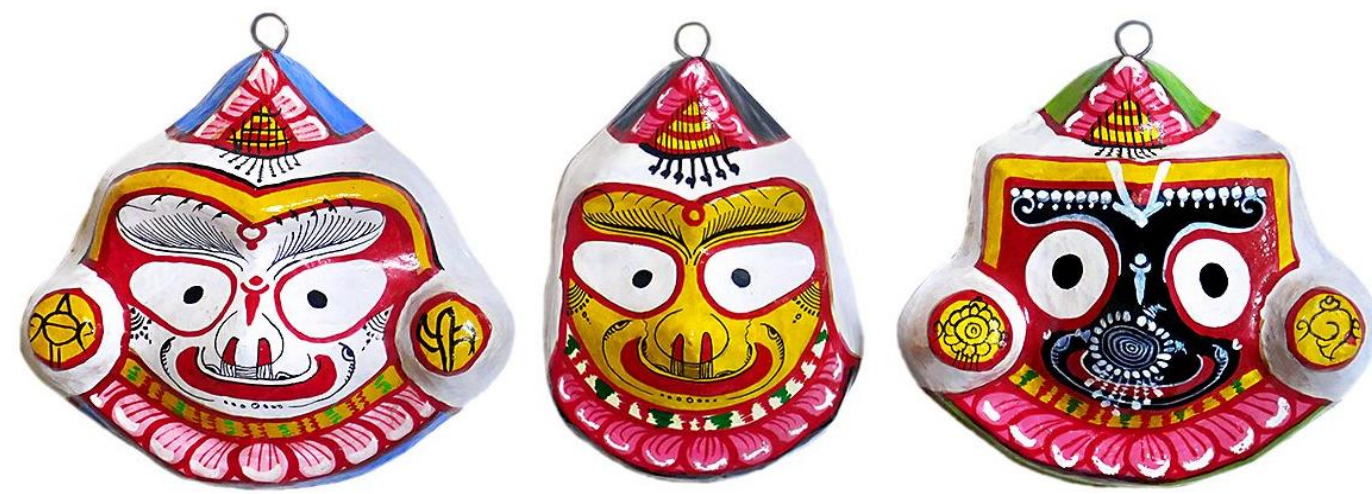
"The word 'mask' has a foreign origin. It can refer to the French term 'masque' or the Italian word 'maschera' or the spenish term 'maiscara'. The word is also considered to have its origins in the Latin words 'mascus'and 'masca' which connote ghost. Even Arabic term 'maskarah'which is another originator of term 'mask' implies jester or man in masquerade. The history says that the masks have been used since antiquity for both ceremonial and practical purpose in India."1
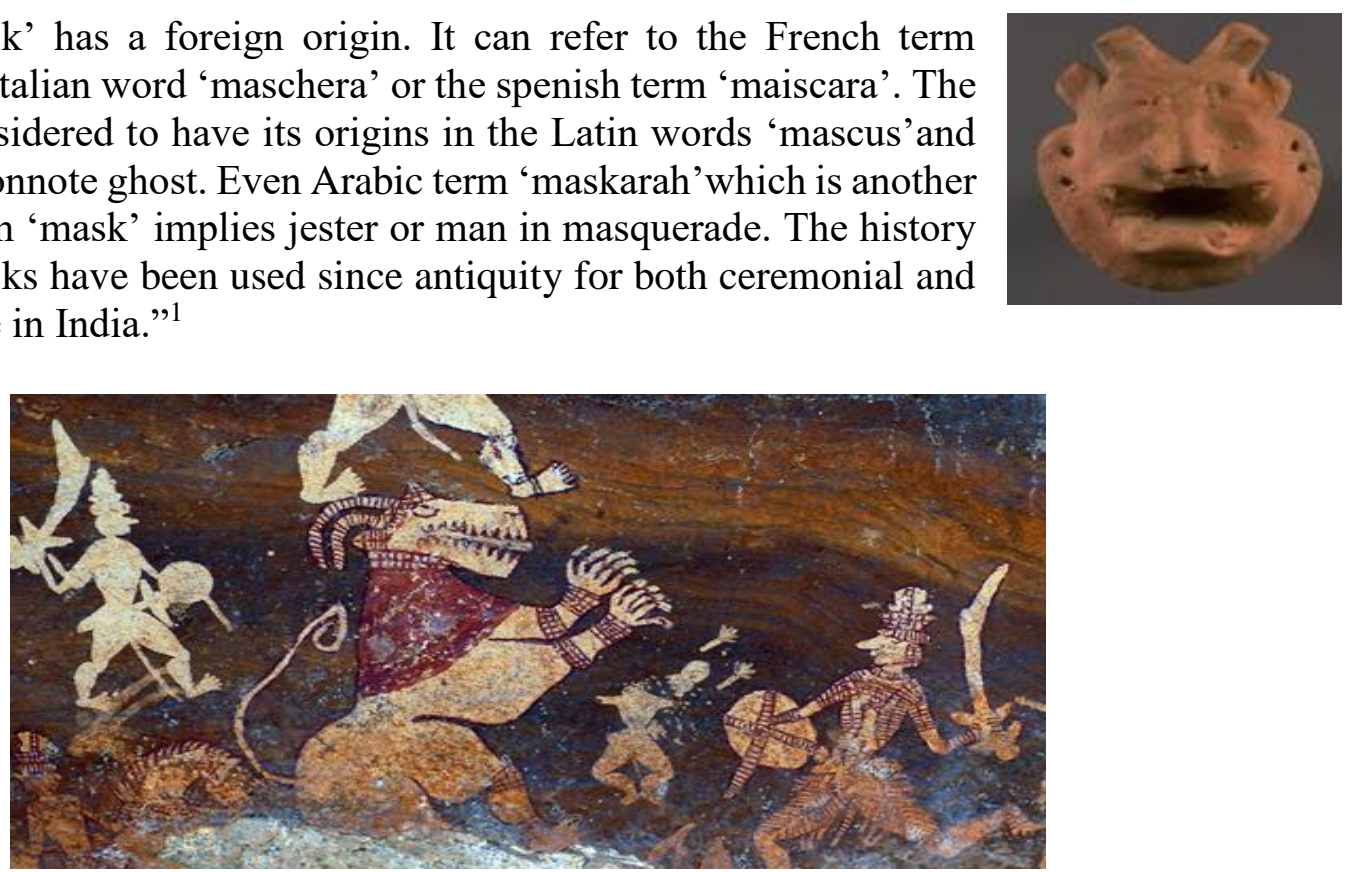

Masks are used to cover the faces for many reasons such as protection, to change the appearance, entertainment, ornamentation and in ritual practices. Mask making is one of the most famous traditional craft of India which is still continuing. Now the mask became inseparable from our lives. There are many masks all over the world used for their expressive power in dance and drama performance as well as in many ceremonial functions, religious and social rituals and in entertainment. ${ }^{2}$

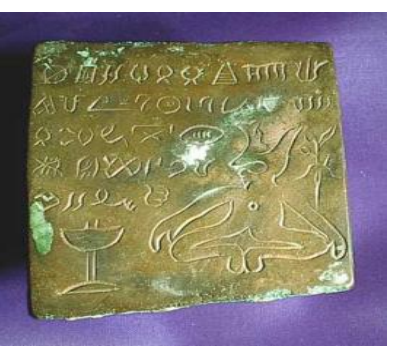

It reflects the innocence of primitive people. The research reveals the use of mask in painted walls of prehistoric rock caves and shelters. (Zoomorphic- having animal characteristic, Anthromorphic-human characteristics; or combination of two). In prehistoric period the mask were probably used for hunting, and taming of animals. While dancing they use the mask as head gear. From the Harappan site a terracotta mask with upright horns, open mouth, beard and small rounded ears is excavated. The mask from Mohenjo-Daro depicts the peaceful face of deity with short horn and long ears lying against the horn, beard face has

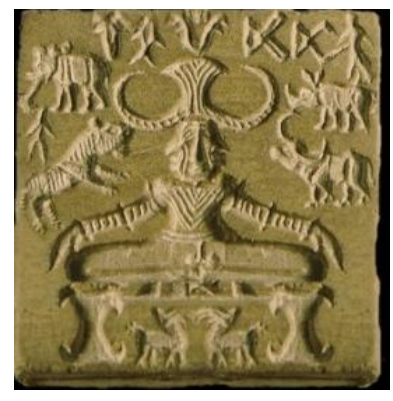
almond shaped open eyes. ${ }^{3}$ Two copper plates 2600-2000 BC, from the site of Indus valley depict the figures of horned deity. The seal with the figure of Pashupati reveals the evidence of mask of the combine figure of both animal and human form. The worship of gods was the integral part of life of Indus civilization culture. ${ }^{4}$

In India, the festival masks are used to represent the deities and mythological characters. It is believed that mask is related with the ancestor cult. In different parts of the country, the rich tradition of Mask has distinct quality. They are usually formalized and highly exaggerated with aesthetic values. The Impact of Vaishnavism, Shaivasm-Shakti cult and Buddhism reflects in various part of Indian culture.

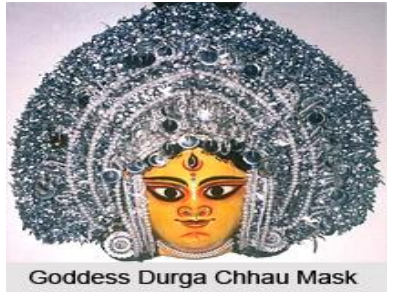




\section{Vaishnavism}

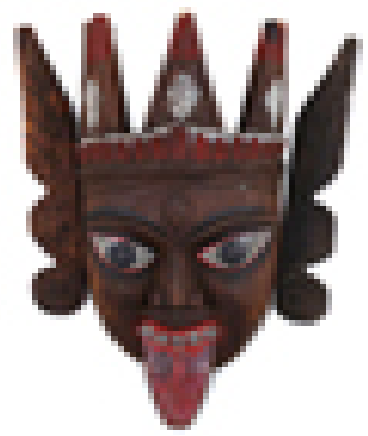

The dramatization of the stories of epic Ramayan and Mahabharat contemplate in many 'Natya and Nratya' of India. Mask plays the main role they help in the personification of character. Bhawna of Majuli (Assam) and Chhau Dance of West Bengal, Garadi of Puducherry represents the various mythological characters, gods and goddess and historical characters. In Assam the Ras-lila performed during the Ras-Mahotsav. The Ankia Nat of Assam is also the mask dance. It is one of the act folk dances. The Sattriya Ankia Bhawna artists of Assam (Ras festival of Majuli) perform the act dance with mask. ${ }^{5}$ The theme of the dance based on the tales of Lord Rama and Lord Krishna reveals the impact of Vaishnav Cult. They use three kinds of masks- Mukha, (face mask) Lotokai mask (face mask in which eyelids and lips are movable ) and Bor mukha (mask that covers the upper body part with jaws and hands etc). ${ }^{6}$

Krishnattanm of Kerala is also the dance -drama based on the life stories of Lord Krishna. The colourful facial make-up with large headgears is made. Therukoothu of Tamilnadu is a street dance based on Ramayan Mahabharat and the Tamil epic. The masks worn by artist are partial face mask. ${ }^{7}$ At the time of Dusshera in various parts of Uttar Pradesh, Central India and many other parts of India Ramlila is performed. The performers use the mask related to their performances. The personification of characters through mask captures the psyche of Audience. At the time the festival Dussherra, the artist wears the mask of Ravan, Hanuman and other characters of Ramlila. Ram nagar is known for making a large number of mukh otas of human and animal forms. ${ }^{8}$ In many states of India like Assam, Haryana, Bihar, Uttar Pradesh at the time of Bhagwat Katha, they use to picturise the related story of Bhagwan Krishna. In Assam the Ras-lila performed during the Ras-Mahotsav. In Raaslila, the Gop and Gopies wear the mask while their dance performances. ${ }^{9}$

\section{Shiva and Shakti Cult and Composite Mask}

The Shiva and Shakti cult are very common in India. The people of West Bengal worship Durga, Parvati, Chandi and Kali. On Shivratri the wooden mask of Kali Mai are worshipped. At the time of Chicken Pox or missals disease Sheetla Mai is worshipped in Baitul district of Madhya Pradesh. ${ }^{10}$ 'Durga-Puja' festival is celebrated with great fervor. Mask is used to portray the character. Kali Nach, Gambhira are the remarkable mask dance of West Bengal. In South and North Dinajpur districts of West Bengal the Gamira mask is used in Gamira dance praise of Gram-Chandi in month of mid-April to mid-May. The Gambhira mask of Malda district of West Bengal are three-dimensional crown shaped wooden coloured mask. ${ }^{11}$ Durga is also worshipped as

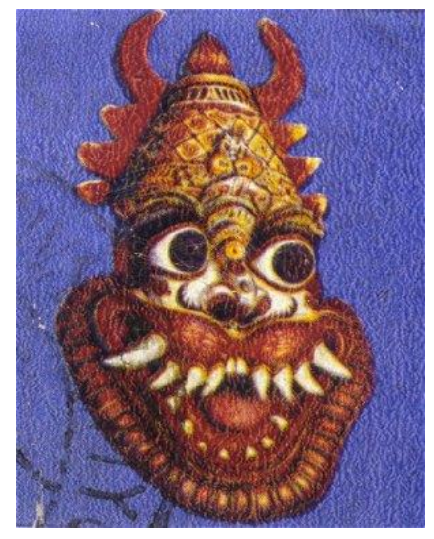
Mahishsasurmardini. The idol of Durga and Kali along with her 'vahan' Simgh in Navratra, narrates the power of Shakti who kills the buffalo headed demon 'Mahishasur.' The narration of the story played with Mask dance. 'Char-gog' is mask of goddess Chandi. 'Char-pagal' and 'Maper-char' are name of mask of West Bengal. In Malabar of Kerela the performers presents the performance 'Kummttikkali' on door to door with painted wooden mask. In Kerela the huge mask 
or 'Kolam' painted in colourful designs, on the stalks of areca leaves are used in folk dance 'Padayani'. The mask are of Goddess Kali (Bhairavi), Yakshi, Yam (Kalan) and birds(pakshi). The masks are long and covered the body up to the chest and abdomen. Thirayattamis of Malabar a festival dance, it is a form of ancient civilization. Theyyam is temple ritual dance of Kerela, is also known as Kali Yattam Narsimha Avtar is one of the incarnations of Lord Vishnu. Many theatre of Karnataka, Andhra Pradesh, Tamil Nadu and Orissa plays the 'Natak' of Bhakt Prahlad, use the Mask of Narsimha. (Composite) ${ }^{12}$ At the time of Ganesh pooja, The Patra, who act as Lord Ganesh wears mask. At the time of Anant Chaturdashi 'Jokkad' wears and Dance in Gond tribe of Madhya Predesh. ${ }^{13}$ In Maharashtra, mask of Bhairav along with lord Ganesh is popular. The other masks are of birds, but gods and goddess mask are in culture. The tribes of Maharashtra, Karnataka and Gujrat wear the demons and ghost mask also, in their mask dance. In Kerala the dancers performs the Bhoota Dance with wooden mask. The characters of Ramlila also wear the mask as per need.

\section{Buddhism}

In Buddhism, celebration with mask culture is also in vogue. Many festivals are celebrated with mask. The painted mask dance of Sikkim is performed by lamas on the occasion of Buddhist festival. Cham is the famous mask dance of India, Bhutan and Tibet. The mask of Padmsambhav (Buddha), Maha Dongcren (a horned mask figure) mask of demon and Yam are prepared for Dance. The mask of Mahankal in Buddhism is prepared for performance. In Hinduism, the Lord Shiv is worshiped as Mahankal (Destroyer). In Ujjain of Madhya Pradesh, the famous Mahakal Jyotirling is situated. At the celebration of Dosmoche festival the Lamas performs sacred the

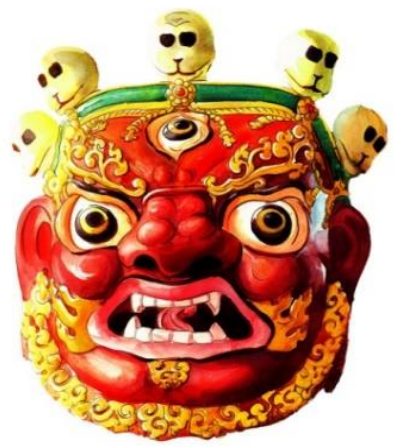
mask dances with great joy and enthusiasm. The Bagpa dance of West Bengal has Tantric concept of Buddhism, it denotes the victory over evil. The masks are colourful and made of wood. ${ }^{14}$

\section{Zoomorphic Mask}

Zoomorphic mask depicts the animals through the mask. Animal mask is continuing in practice since prehistoric age. Mythological and real animal acquire the space in folk and tribes of India. The tribes of Madhya Pradesh wear the wooden mask of various moods. Not even animal, they use to carve snake and insects also for the mask. Tiger mask is used for Bagh Nritya of Orissa and Puliyattam of Tamil Nadu. Lion mask is used in Lion dance of Purulia. The Lama dance of Kinnaur, ${ }^{15}$ Baghori Dev- Sarguja district and Baghoran Dev -Mandla of Madhya Pradesh. ${ }^{16}$ and Himanchal Pradesh is also the famous for lion dance of the local tribe of Chamba. Jackal mask of West Bengal is also popular. Yak is the main animal of Himalaya region. The two performers hold the Yak head and act as a Yak. The other dancers used to wear the mask while dancing. Singhi Chaam is a mask dance of Sikkim, dedicated to Lord Padsanbhav. Cow mask is used in Ramlila of Banaras. In the month of 'Chaitra' (the first month of Hindu varsh) to honour the deity Vasuli, the people of Orissa performs the Chaity Ghoda (Horse) Dance. The horse dance is also performed in some part of Uttar Pradesh and Rajasthan at the time of Holi festival. The performer in royal costume, holding the sword performs the dance with dummy horse as a rider. Keelu Kudure is also a dummy horse of Karnataka. The horse dance of Tamil Nadu is known as Poikal Kudirai Attam. 
The dancers attached the dummy horse at the waist and imitate the movement of horse. In Gwalior region of Madhya Pradesh this is known as 'Dul-Dul Ghoda'. The dancers performed their dance in front of Wedding Procession. ${ }^{17}$ In Bihar at the time of 'Chaitra Parv' the performers of Chhau performs the 'Mayoor dance' with the mask of Peacock. Mayur Nritya of Uttar Predesh, Saraikela Chhau of Jharkhand, Mayil Attam of Tamilnadu is also the peacock dance. ${ }^{18}$ Hidden treasures of India at the time of 'Shahi Jatra' (royal procession) of Orissa actor wears the mask of Garud, animals and birds along with the mask of god and goddess. In Arunachal Pradesh the Monpas represents the popular dragon dance. The Bardo Chham dance of the Arunachal Pradesh is a religious folk dance to protect the community from the evil forces. The dancers wear animal mask while dancing. The lamas of Himalayan region portray the divinities of Dringungpa pantheon with the mask. Nongkrem is the famous mask dance of Meghalaya. ${ }^{19}$

"The form and design of the mask have to be conceived keeping movement in mind. It is essential for the craftsmen to have a very subtle and innate sense of movement which they infuse into their design." 20

In many tribal customs of India they use the mask as a part of costumes. Mask is generally used to conceal the identity or to transform the character.

\section{Material}

"The leaves may be used as a first material in the formation of Masks in ancient time, but in later age clay and wood were used. After that cloth and paper Mache were used by craftsmen." 21

All masks have some elements and principles of design. They serve multiple functions as they are the functional art form. Mask are made by wood, paper maieche, a few are made of wrought iron. ${ }^{22}$ Leather, bones, shells, beads, fibers, human or an imal hairs and feather is also used ${ }^{23}$ Tribal of Madhya Pradesh make carved wooden mask of animals and insects. Maria tribes used the wooden mask with bison horns in red coloured. Mukhada or mask is made of pumpkin or guard skin, waste paper, wood and card board, pumpkin seeds is used to make the teeth. Moustaches and beard are made by the hairs

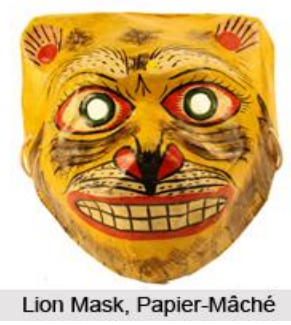
of goats or bears. Mouth nose and ears are made honey bee wax. For decoration aluminum foil, gloss paper, feather of birds or peacock are used. ${ }^{24}$ The craftsman of Purulia, West Bengal make wooden mask for Chhau dance. In Nepal, wood is used to make mask. Mask could be made by single piece of wood or it can be mechanical with movable parts as the eyes open and shut. Brass and Zari is used for making Ramlila Mask. Stalks of areca nut fronds are used to make Kolam. These perishable masks are painted with natural colours viz turmeric fruits and vegetable dyes. ${ }^{25}$

Today new generation are using the new material viz pearl, artificial stone and others, which are easily available and cheap.

\section{Conclusion}

"Mask represent a living culture and were created not only for several religious or ceremonial purposes but also for beautification (Venetian masks) or as a masquerade to hide identity" 26 
Masks are used generally in rituals, dance and theatre. Masks are also the part of megico- religious practice. It plays the vital role and forms a silent language which defines the soul of the human expression and feelings. Apart from human character the mask is used to personify the mythological, divine, composite and zoomorphic characters which help to make a bridge between an actor and the spectators in reciprocation of sentiments.

Man is the creation of nature, he cannot change the originals but he has skill to recreate what he feels. Art, literature and culture are his recreation. He used line, pictures, photography, sculpture, symbols and myths to present his emotions. The mask helped him to overcome from his weaknesses and to inculcate the truth and portray the different moods. Thus it becomes the object of representation which represents the totality of the arts and culture of particular region and community.
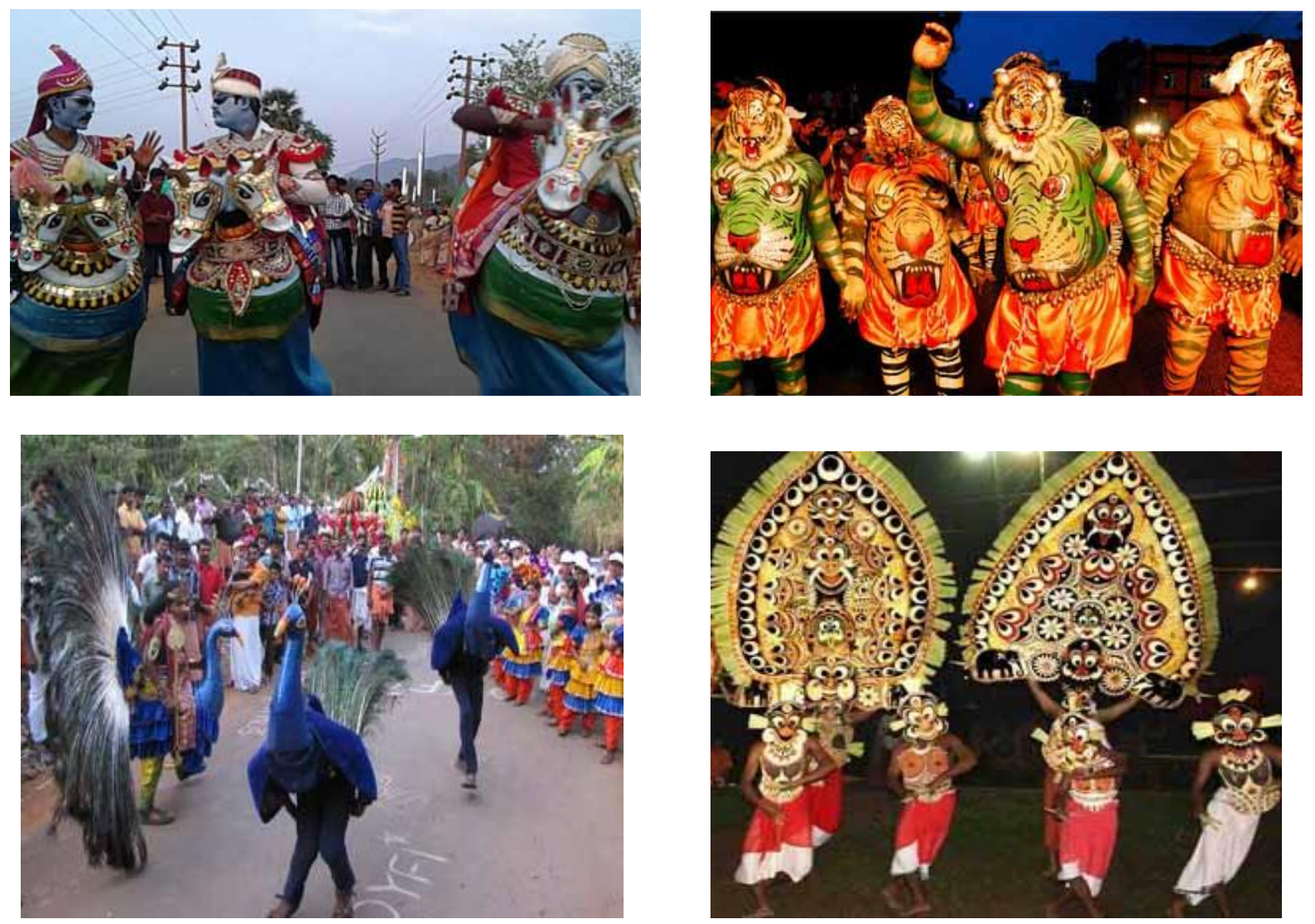

\section{References}

[1] https://m.indianetzone.com/Article/masks

[2] www.historyofmasks.net:HISTORY OF MASKS- ANCIENT USE OF MASKS

[3] www.Harappa.com/slide/mask.

[4] Shinde Vasant and Wills R. J.: A NEW TYPE OF INSCRIBED COPPER PLATE FROM INDUS VALLEY (HARAPPAN) CIVILISATION, Ancient Asia, 5:1, pp1-10, DOI;http.//dx.doi.org/10.5334/aa.12317

[5] Guin Madhuri:(2017) dolls of India MASK: REFLECTION OF CULTURE AND RELIGION 
[6] Rumela Basu, Dhyaneshwar Vasant Kurhade(2015 ) ILLUSTRATED: 7 MASKED DANCES YOU CAN WATCH IN INDIA; National Geographic Traveller India.

[7] Ibid

[8] www.indianetzone.

[9] Guin Madhuri: (2017) dolls of India MASK: REFLECTION OF CULTURE AND RELIGION

[10] Tiwari Kapil, (1999) PRATIROOP, Madhya Pradesh Lok Kala Parishad Bhopal, fig-25

[11] www.indianetzone: WOODEN MASK OF WEST BENGAL.

[12] Guin Madhuri: (2017) dolls of India MASK: REFLECTION OF CULTURE AND RELIGION.

[13] Tiwari Kapil, (1999) PRATIROOP, Madhya Pradesh Lok Kala Parishad Bhopal, fig-42

[14] Guin Madhuri:( 2017) dolls of India MASK: REFLECTION OF CULTURE AND RELIGION.

[15] Ibid

[16] Tiwari Kapil, (1999) PRATIROOP, Madhya Pradesh Lok Kala Parishad Bhopal, fig37-47

[17] Nirgune Vasant.(2010)“MADHYA PRADESH KE LOK NRATYA” Ayukt, Jansampark Sanchanalaya, Banganga, Bhopal. Pg- 92-93. / An interview with Laxmi bajpai

[18] Sheesh:(2018) INDIAN FOLK AND TRIBAL DANCES; https://htoindia.com/blog/india-folkand-tribal-dances/

[19] Guin Madhuri:( 2017) dolls of India MASK: REFLECTION OF CULTURE AND RELIGION

[20] Suresh/Chitra Subramanian (2014)

[21] www.indiatoday.in/magazine/societyandthearts

[22] Tiwari Kapil, (1999) PRATIROOP, Madhya Pradesh Lok Kala Parishad Bhopal,

[23] Rakheja Henna (2017) UNMASKING ART: A COLLECTION OF EXOTIC MASKS FROM DIFFERENT STATES OF INDIA” Hindustan Times; New Delhi 2017

[24] History of Masks- www.slideshare.net/mobile/absenicconstruction/the-history-of-masks

[25] Tiwari Kapil, (1999) PRATIROOP, Madhya Pradesh Lok Kala Parishad Bhopal,

[26] Rumela Basu, Dhyaneshwar Vasant Kurhade:( 2015) ILLUSTRATED: 7 MASKED DANCES YOU CAN WATCH IN INDIA; National Geographic Traveller India.

[27] Pandey Alka/ Shilpa R () LIVING CULTURE OF MASKS; https//www.goole.com/thehindu.com.

*Corresponding author.

E-mail address: anjali_pandey11@yahoo.com 